\title{
Creating Physical 3D Maps Using Rapid Prototyping Techniques
}

\author{
Wolf-Dieter Rase \\ Federal Office for Building and Regional Planning, Bonn, Germany \\ wolf.rase@t-online.dewww.wdrase.de
}

\begin{abstract}
To build multicolored physical models of three-dimensional cartographic objects computer-controlled devices can be used which were developed for the fast and inexpensive production of mechanical parts. Such objects can be a landscape with relief, a city model, or a continuous surface interpolated from statistical data. The main groups of rapid prototyping technology - aggregation, removal and, transformation - are presented, including the machinery to build physical models, and a new relative, laser subsurface engraving. Examples of surface models built by a $3 D$ multicolor printer demonstrate the capabilities of the technology. A new $W W W$ based service is described which enables the production of $3 D$ relief models covered by satellite imagery, topographic maps and user-supplied GPS tracks.
\end{abstract}

\section{Virtual and physical reality}

The enhanced cost-effectiveness ratio of computers and graphic peripherals has provided advanced methods to generate photo-realistic scenes, which are known as virtual reality (VR). Developers and users of geographical information systems have adopted VR to visualize spatial objects. Computer graphics and VR have also facilitated the transition from static planar maps on paper or flat displays to perspective and stereographic representations, which can also include the time dimension. Such dynamic visualization has been made possible by high-performance desktop computers and high-capacity distribution media, such as the World Wide Web, the CD-ROM and DVD.

Perspective drawings on 2D media take advantage of the viewer's lifelong experience in recognizing and interpreting depth cues in pictures. The 
main shortcoming of using perspective drawings for cartographic applications is the inability to obtain distances and directions from measurements in the picture, although interactive software provides solutions to that problem.

Stereoscopic displays make use of the ability of the human brain to construct a 3D mental model from two slightly different images, one corresponding to each eye. Stereo images may be provided by binocular viewers, shutter glasses, lenticular and barricade displays. Stereoscopic viewing can also be induced by non-binocular optical effects, such as SIRDS (single image random-dot stereograms) or chromostereoscopy (Rase 2003).

Despite the availability of virtual reality technology, physical models of buildings are still requested in architectural competitions, even though VR techniques are able to provide more visual information than a model. For example VR allows interiors to be visualized from different viewpoints and under varying light conditions during a walk-through, or the view through a window, in both directions, can be generated. Why are those rather expensive architectural models still requested? One reason may be that the cost of the model is a marginal quantity compared to the cost of the competition, let alone the real building. Probably architects have also a fondness for the haptic experience, the opportunity to feel an object with their own hands.

Physical models have the advantage over 2D drawings that slight movements of the head or body suffice to compare heights, to solve viewing ambiguities or to reveal parts of the model that might be obscured in a fixed view. In case of non-dynamic media multiple drawings it may be necessary to present all parts of a scene. The quest for haptic experience may be valid not only for architects but also for decision-makers in regional planning with a limited experience in map reading. It is suspected that under certain circumstances a real 3D model is able to transmit the cartographic message much better and faster than a two-dimensional map.

\section{Rapid prototyping}

Rapid prototyping $(R P)$ is the automatic construction of physical objects using solid freeform fabrication within short timeframes. Numerically controlled machines capable of the production of mechanical parts have been in use for more than four decades. Advances in microelectronics have led to computer-controlled devices which are able to build physical models at reasonable cost. The prototypes serve mainly to judge on the form and appearance, in certain cases to evaluate the mechanical function (Grenda 2009). Usually the prototypes are not exposed to the mechanical stress that their real counterparts have to withstand, for example the prototype of a steering wheel for a car. Thus it is not necessary in most cases to use the same material of which the final part will be made. 


\subsection{Main groups of rapid prototyping techniques}

The different technical approaches for the computer-assisted production of parts can be subsumed under four headings with equivalents in the fine arts:

- Removal: A block of material is cut with a tool that removes successively small quantities of material until the final form is reached, as a block of marble is transformed into a sculpture (the Michelangelo method).

- Transform: The material is formed by pressure and heat, as a blacksmith forms a red-hot bar of iron (the Chillida method).

- Aggregation: A part is built up from small amounts of material, in the same way a sculpture or a scale model is formed in plaster or some other plastic material (the Rodin method).

- 3D drawing: tiny points inside a glass block are melted by a laser beam and become opaque (the Dürer method).

An example of the Michelangelo method is numerically controlled milling. Rotating tools of different size and shape moving in three and more degrees of freedom carve material from a block of metal, wood or plastic until the final form is reached. NC milling is slow and expensive compared to the other techniques available today. Coloring must be added in a manual process, for example by airbrushing, or in a transitory mode by projecting an image onto the model with a beamer. An exception is the production of large relief models by the company STM (www.stm-usa.com) using computer-controlled inkjet nozzles moving in three dimensions to apply texture on the surface. The machinery is unique, so the models have to be produced in Fillmore, CA, and shipped to the customer.

The artist Eduardo Chillida created huge metal sculptures by industrial forging of iron rods and bars (one of his sculptures is placed in front of the Office of the Federal Chancellor in Berlin). The transformation by heat and pressure is also used to create multiple copies of 3D maps. In France bookstores offer terrain models of regions and départements, depicting height, rivers, streets and settlements. The 3D models, available at moderate prices, are made by thermoforming a color-printed foil by applying heat, vacuum or pressure using a mould, which, in most cases, is produced by NC milling (www.georelief.fr).

The aggregation of material, the Rodin method, has the greatest potential for rapid prototyping in general and for the creation of city and cartographic surface models in particular. The integration of coloring into the production process opened new horizons for cartographic applications of rapid prototyping (more in the following section).

The 3D analogy to 2D drawings is laser subsurface engraving which, strictly speaking, does not belong to the rapid prototyping family, but uses the same data and files to encode the model, and computer control to move the laser beam along three axes. 


\subsection{Printing in three dimensions}

The most frequently used technologies for rapid prototyping belong to the Aggregation group. Stereolithography was the first technique for rapid prototyping. A computer-controlled laser beam induces a phase change in a thin layer of photosensitive liquid. The liquid changes phase - becomes solid by polymerization - where the laser beam hits the surface. A new layer is then built on top of the solidified layer, and the procedure is repeated until the object is finished. Other devices aggregate drops or streams of thermoplastic material to build the model. The material is heated in a multi-nozzle printhead. The liquid material is deposited on the previous layer. Outside the printhead the material cools down and solidifies again. There were also devices that use laser-cut paper sheets laminated to a block (LOM), but they have been superseded by less expensive techniques with more capabilities, such as the powder-based devices which are used now for most applications.

A thin layer of a powder, such as starch, plaster, photopolymer or metal, is deposited onto a building platform. The regions of the layer that are to

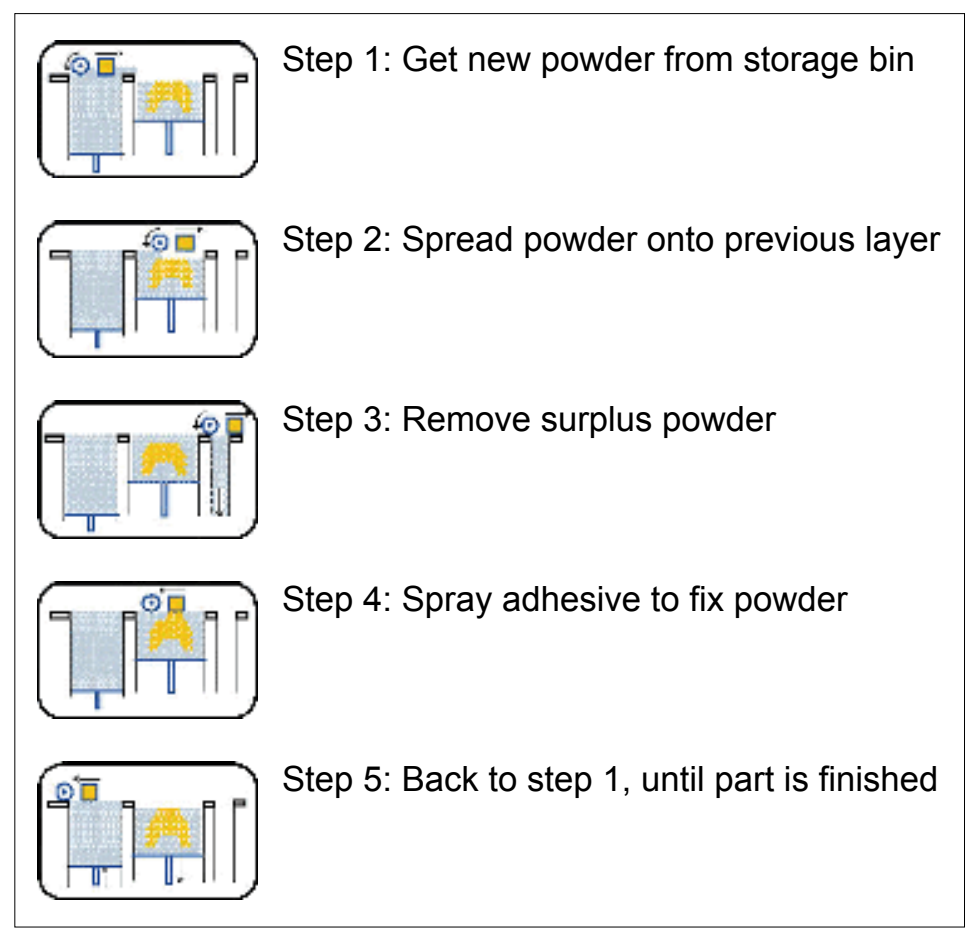

Fig 1. Building steps in a 3D printer 
become part of the model are fixed by selective spraying of an adhesive, by polymerization with an UV light beam, or by local heating with a laser beam (selective laser sintering, SLS). When the first layer has been fixed the second layer is deposited, and so on, until the final layer is accomplished (fig. 1). After completion of the model the loose powder is removed by a sort of vacuum cleaner and an air jet. Most devices allow recycling of the unused material.

Which process or device should be used depends on the purpose for which the prototype is intended. For instance, stereolithography achieves very smooth surfaces, but is expensive. Selective laser sintering, also called direct metal printing, produces metal parts which are stronger than parts from other processes. The artist Bathsheba Grossman uses direct metal printing to create multiple copies of sculptures based on mathematical concepts (www.bathsheba.com). A combination of starch powder and wax can be used to build a pattern for investment casting. The part is covered with refractory slurry and then the wax is vaporized and replaced by the molten metal. Some powder materials can be finished with tools used for wood and electroplated subsequently to give the appearance of metal.

\subsection{Multicolor 3D printers}

Color is an essential graphic variable in cartography and model visualization. Until a few years ago the direct application of color during the buildup stage was not available, and the raw models had to be colored manually. The application of color must be integrated into the building process of the model to keep the production within a reasonable cost frame. In recent years new RP devices were developed which can apply color in high resolution and in many program-controlled shades, which makes it feasible to use the technology to build physical models of cartographic objects. The rich color spectrum and the use of standard inkjet printer parts probably caused the manufacturers to call their devices 3D printers.

The first 3D printer with integrated high resolution color capability was introduced in 2001 by the company ZCorporation (www.zcorp.com). In addition to the transparent glue the device applied three colored glues containing pigments of the subtractive base colors cyan, magenta, and yellow. The finished model is usually infiltrated with a hardening liquid, such as epoxy rosin or cyanoacrylate, which enhances the color luminosity, improves the mechanical strength and protects against high humidity.

The 3D printers of ZCorporation are still the only devices on the market (also sold under a different brand name) that provide multi-colored parts. For the top member of the family, the 3D printer Z650, a black print head was added to solve the problem of the imperfect gray and black shades created by mixing cyan, magenta and yellow pigments. The Z650 provides real CMYK colors with a resolution of $600 \times 540$ dpi. The capability to provide 
color integrated into the build process opens many new applications for RP aside from cartography and GIS. For instance multi-colored models of molecules, buildings, city models or plants can be produced. There are many potential uses in medical visualization improving clinicians' comprehension and understanding of data from $\mathrm{x}$-ray or magnetic resonance scanners.

The software for the $3 \mathrm{D}$ printers slices the numerical representation of the model into layers of user-selectable thickness, in the range 0.089 to 0.102 $\mathrm{mm}$. The thickness of the layer determines the resolution in the $z$-direction, and hence the production time. A value of $0.1 \mathrm{~mm}$ was used for the surface models referenced here. From two to four layers can be built per minute. The Z650 printer can handle parts up to 254 × 382 × $200 \mathrm{~mm}$, dependent on the model size and the number of base colors used.

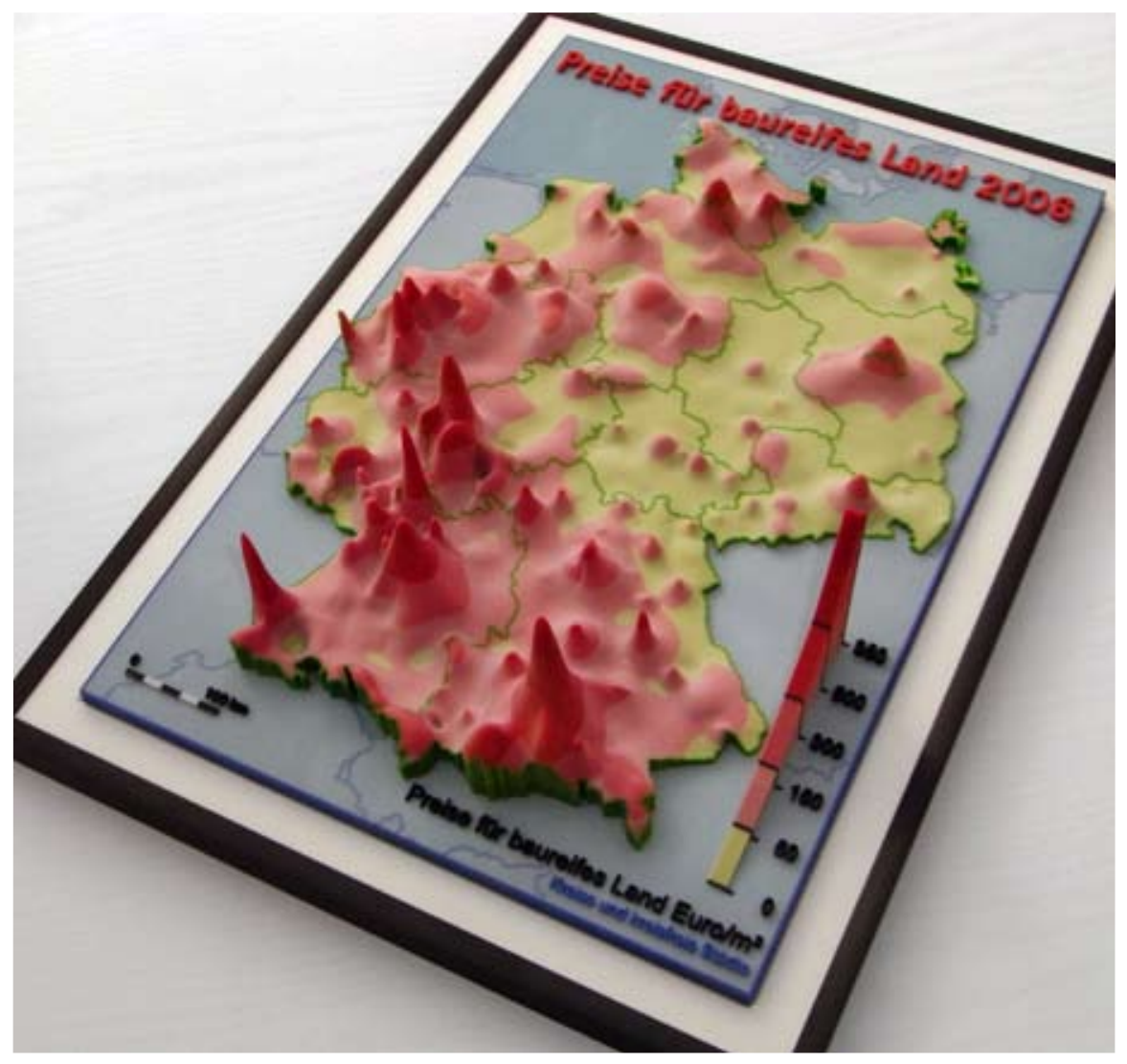

Fig. 2. Physical model of an interpolated smooth surface representing the average prices in Euro $/ \mathrm{m}^{2}$ for building lots in Germany 


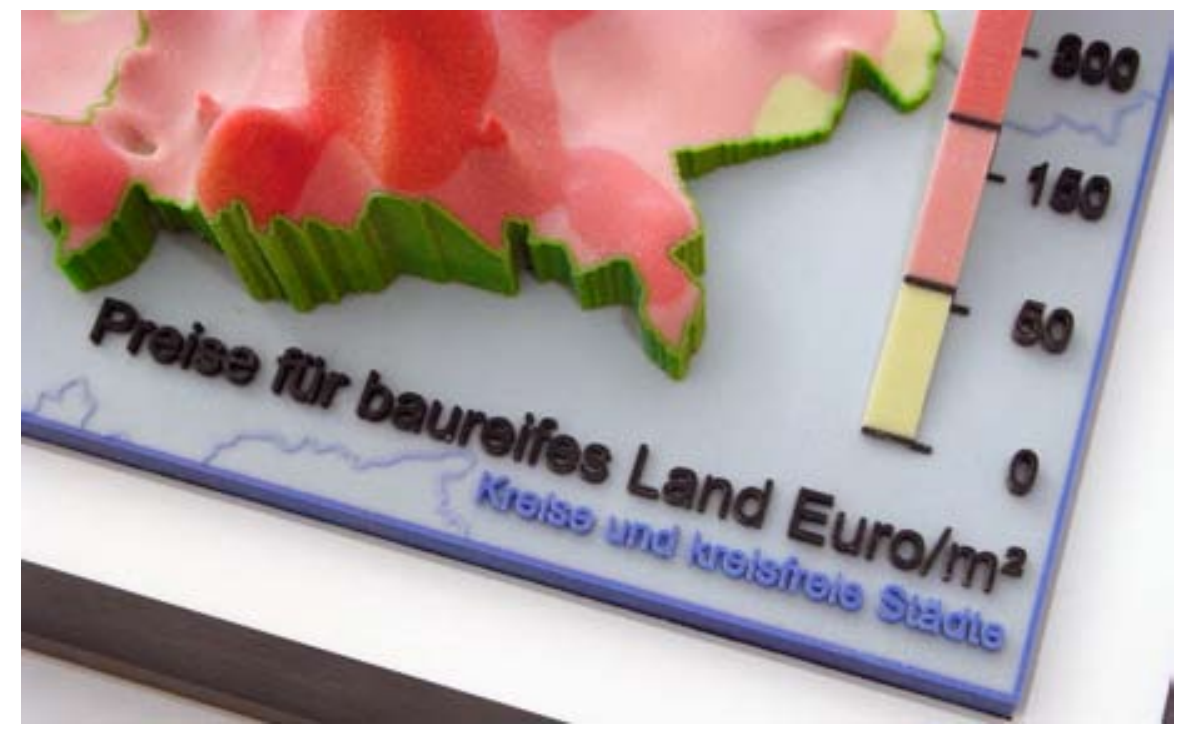

Fig. 3. Enlarged part of surface model in fig. 2, legend and text

\subsection{Laser subsurface engraving}

Laser subsurface engraving (also known as laser etching) is performed by a computer-controlled device where a focused laser beam melts a tiny spot in a glass block, destroying locally the transparency of the glass. The molten spots blend into a 3D picture, which might represent a building, a human portrait, or a cartographic surface. The laser beam and its focus are moved in relation to the glass block using data derived from a numerical representation of the object. It is obvious that the melting process has to start with the lowest layer, otherwise the laser beam would be occluded.

The equivalent $2 \mathrm{D}$ representation is a pen drawing or an etching which is why I like to call this the Dürer method. The object inside the glass block is monochrome (fig. 4). Putting it on a pedestal providing adequate illumination is advisable to insure good visibility. Nearly identical VRML files as with the 3D printer were used to generate the surfaces inside the glass block. The files were sent by e-mail to the company which builds the computercontrolled laser engraving devices (www.vitro.de). The manufacturer of the device offers now additional software to its customers, intended to improve the visual appearance of the models in the glass block. A franchise organization operates shops in several countries, providing etching devices and 3D cameras necessary to do 3D portraits on the spot (www.looxis.com). Some of these shops are able to accept 3D files and produce the laser etching for customers. 


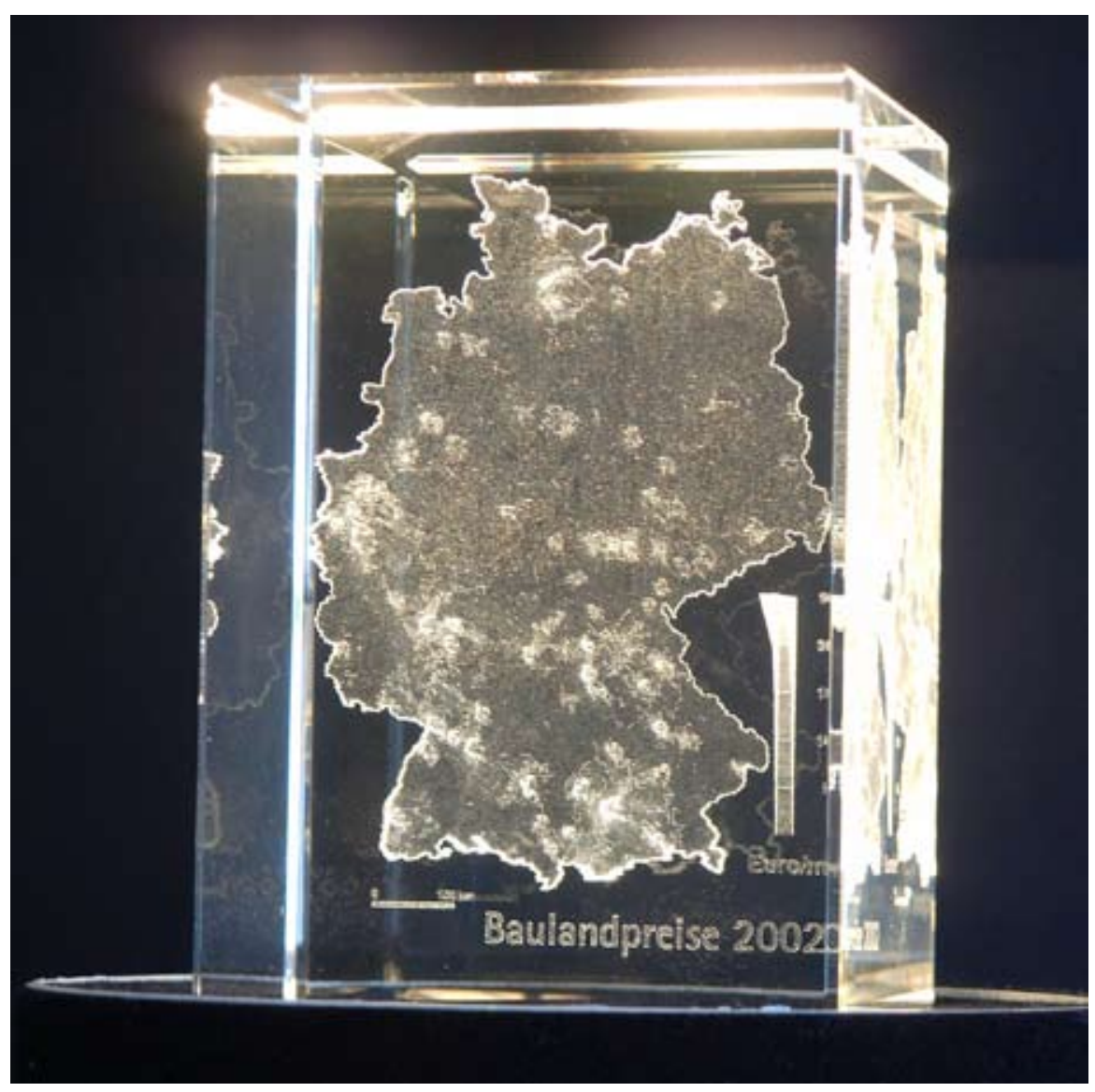

Fig. 4. Glass block with laser-etched 3D surface

\section{Examples of cartographic 3D models}

For the visualization of cartographic surfaces generated from demographic, socio-economic or accessibility data a number of physical models were produced. Only three typical examples can be presented here. At first a few details on the numerical definition of the models and the production workflow are given.

\subsection{Model representation and workflow}

The continuous surfaces depicted in the models were interpolated from point or polygon data, with the geometric base data prepared using a standard GIS 
package (ESRI ArcGIS). The interpolation of the surfaces and the creation of the numerial representation of the 3D models were done using our own software.

The skin of the model - surface, base, legends, text strings - is represented by an irregular triangular mesh which can be stored in different file formats used for 3D models. In our case the VRLM97 or PLY file format were used. Many CAD programs and viewers are able to display VRML files for visual inspection of the models, including syntax checks of the triangular mesh.

It is possible to cover the surface with a texture defined in a geo-tagged raster file to depict lines, text strings and other relevant geometric information. The distortion of the pixels on steep slopes of the surface, however, results in a fuzzy appearance not acceptable for maps. Thus the boundaries and other lines are represented by thin tubes composed of small triangles. The skin of the legends and $3 \mathrm{D}$ text strings are also represented by triangular meshes.

The 3D text is generated by extruding the glyphs (polygons) defining the characters in the TrueType font files. The graphic resolution of the glyph is user-selectable, and depends on the actual character size. Any TrueType font can be used, provided that the syntax of the glyphs is correct. The same approach is used to construct $3 \mathrm{D}$ point symbols from symbol definitions in TrueType fonts, such as the tiny planes representing airports in fig. 6 .

The interpolation and the triangle generation including the meshes representing the tubes, areas, legends and 3D text, are done with our own software. Standard viewers for 3D models are used for simple visual checks of the models. Before the files are transmitted to the 3D printer a thorough check is performed to reveal and correct serious problems which could spoil the actual build process on the $3 \mathrm{D}$ printer.

Even though 3D printers now cost less than half as much as a highquality mechanical $2 \mathrm{D}$ plotter did about 20 years ago, it is not economical to buy a $3 \mathrm{D}$ printer for only occasional use. So the services of a contractor were used to build the models (www.4dconcepts.de). The VRML files with the model representations were sent to 4Dconcepts as attachments to e-mails. Assuming that no errors are detected during an extra check at the contractor's premises, the model is built on the printer, infiltrated with the stabilizing liquid, and then returned to the customer by a parcel service.

\subsection{Surface of average prices for building lots}

The heights of the surface in fig. 2 represent the average prices for building lots, estimated from actual sales in previous years. Interpolation of the polygon-based data (counties in Germany) was performed using the pycnophylactic interpolation method (Tobler 1979; Rase 2009). Figure 3 is a closeup of the same model, showing lines, legend and text strings. 


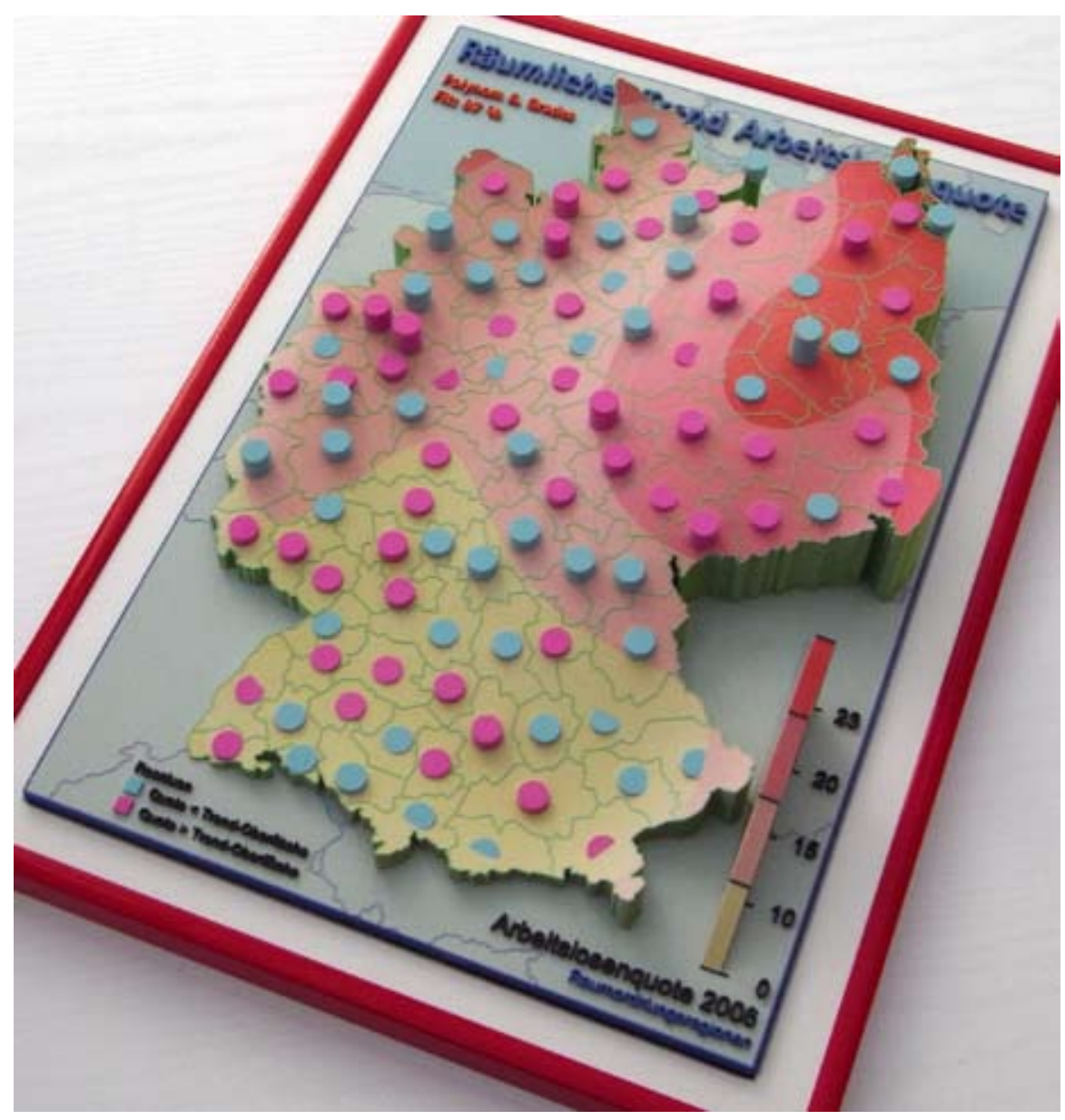

Fig. 5. Bivariate trend surface (order 5) and color-coded cylinders representing the values of the residuals. Cyan: residuals are negative (actual values less than the surface values); magenta: residual values are higher than the trend surface.

\subsection{Trend surface analysis of unemployment}

Figure 5 is a photograph of a model representing a trend surface interpolated from unemployment data. A bivariate least-squares polynomial of order 5 describes the overall spatial trend of unemployment, with high values in East Germany and low values in Southern part of Germany, as expected. The representation of the surface is supplemented by columns representing the residual values, the deviation of the actual value at each point from the value of the trend surface. Because the negative value (unemployment 
less than the trend) cannot be visualized by holes color codes are be used to express negative (cyan) or positive residuals (magenta). In Berlin and the region southeast of Berlin, for example, the actual values are lower than the trend, with columns colored cyan.

\subsection{Travel distance to airports}

The model in figure 6 represents a variable resulting from accessibility computations for the railway and road network in Germany. The heights of the surface are proportional to the average time distance in minutes using a car to the next airport in Germany and outside Germany in the vicinity of the

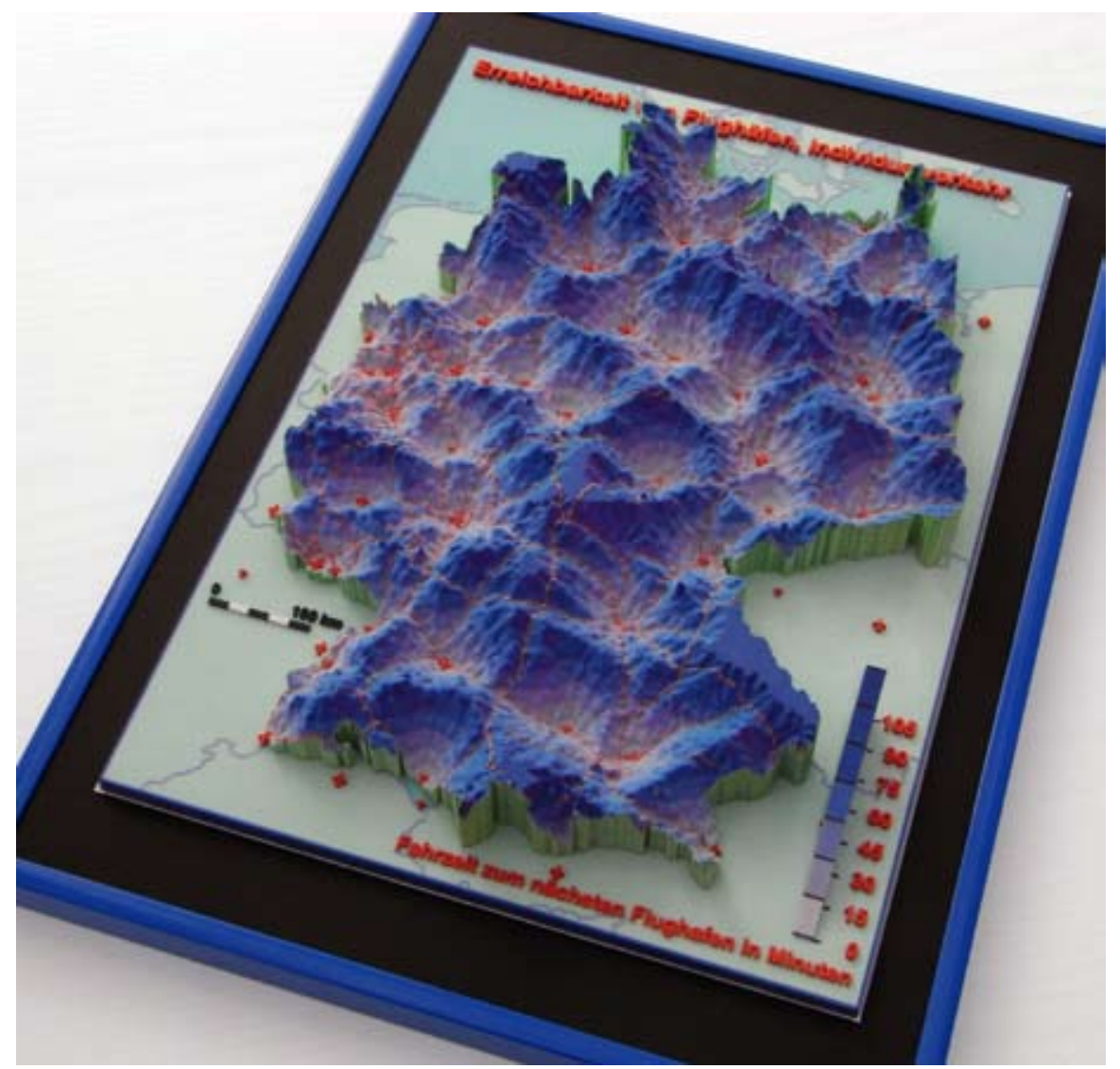

Fig. 6. Surface of time distance to the next airport (accessibility). The surface heights are proportional to the travel time by car to the next airport in Germany and the airports in the vicinity of the outer boundary. 
border. The surface was interpolated to a regular grid from the time distance values at the access points (ca. 20,000) in the network, using the Modified Shepard interpolation method (Renka 1988). At the points near to the airports the surface is almost zero (minmum travel distance). The highest values occur at the peripheral regions.

\section{Relief models with user-selected texture}

The most recent addition to the facilities for creating "true" 3D models is the WWW-based service offered by LandPrint (www.landprint.com). After downloading a Java applet the user can select any place on earth by typing a name. The application zooms in to that place, provided the name is stored in the data bank. The user can define a window and select a multiplication factor for the height from 1 to 5 . The textures overlaid on the relief include satellite images and topographic maps at different scales, at the moment US maps only. The relief data and the satellite imagery are provided by Google Earth. The use of Virtual Earth data is planned.

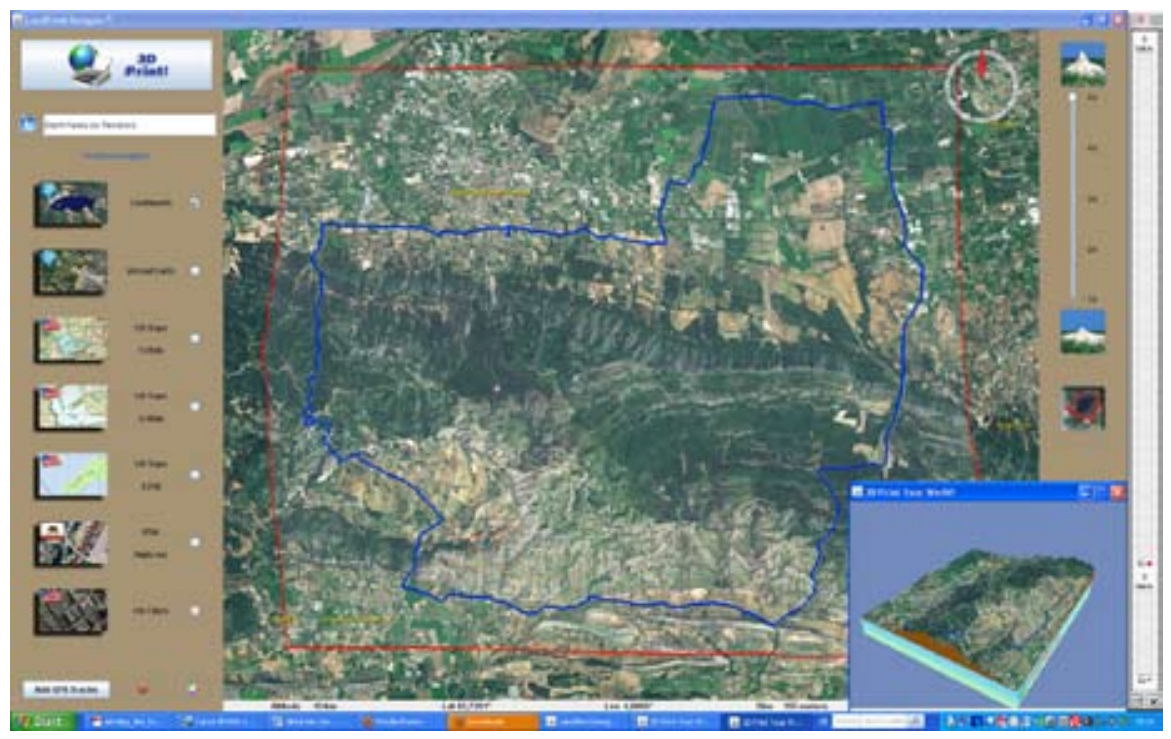

Fig. 7. Screenshot of the user interface to create a the relief model.

Location: Chaîne des Alpilles and city of Saint Rémy-de-Provence, France. Red line: window; blue line: GPS track recorded during a bicycle tour. Small window at the lower right: 3D model preview. 
Relief models intended for regional, environment or traffic planning, recreation development or disaster prevention and analysis can be covered not only with satellite imagery, but also with topographic maps. At the moment only topographic maps of the USA are available. The application of usersupplied geo-tagged imagery is in preparation.

The customer can upload his own GPS tracks to be displayed on the relief model as lines in a user-selectable color. The tracks are usually collected automatically by a GPS recorder during a roaming, canoeing, biking or geocaching tour. The addition of GPS tracks enable outdoor-oriented customers to build their individualized relief models, including their own routes, e. g. as a reminiscence of an outstanding tour in a beautiful environment, or to impress their friends by exaggerating the height factor. The relief models can be built in different sizes up to $25 \times 25 \mathrm{~cm}$. The company ships the models to the customers by a parcel service, but only within continental USA. The prices for the models are very competitive.

For European customers interested in building personalized relief models two European companies so far have licensed the software from LandPrint (as of November, 2009). A Danish firm (www.3dlandprint.dk) offers the service with its website in Danish, but is considering to add web pages in English. The other licensee is located in Great Britain (terrainprint.co.uk). Both firms ship the models to customers in Europe, and are preparing to provide European topographic maps.

\section{Summary}

Physical models of GIS objects are unlikely to replace paper maps or virtual reality techniques. However, a model has all the advantages of a perspective drawing or a stereogram. In addition, viewing ambiguities, such as the inversion of the depth impression, a recurrent problem with 2D drawings and sometimes also with stereograms, can be resolved by a minor movement of the head or body.

The estimation of distance and height within the model is easier with a physical model due to the lifelong experience with 3D views. When a group of people are trying to grasp a spatial situation or process a physical model can have advantages over VR methods. VR equipment is still expensive, less transportable than a physical model, and is not usually able to support multiple users. The production of a physical model, to be fair, is not cheap either, although the prices became more affordable recently.

A physical model can be used for representative and promotional purposes, for example on display in the entrance hall or an office, or exhibited at a fair. In this context models have an important job as conversation pieces. The technical explanation how the model was built can lead to a discussion of the problem that the model is trying to clarify. This is very important for 
environments where decision makers have no immediate relationship with spatial science, GIS or cartography. The model is the medium to introduce the message in a roundabout way, a kind of subversive cartography. An illuminated glass block with the etched object inside falls into the same category, as an eye-catcher or conversation piece. It can also serve as a rather inexpensive theme-related trophy or a personalized present.

Something unexpected happened when I showed these models to visitors or colleagues for the first time: nearly everyone spontaneously tried to touch the surface of the model. To touch the material and the surface forms, to use the haptic sense, is obviously a basic desire, equivalent to the desire to use the other senses. Touching is not reserved for people with a visual handicap, although they would certainly benefit from the economic advantage of producing special maps by rapid prototyping techniques (see also Koch 2009, Schwarzbach et al. 2009).

\section{References}

Grenda, E (2009): Printing the future. The 3D printing and rapid prototyping sourcebook, $3^{\text {rd }}$ edition. Castle Island Co., Arlington, MA http://home.att.net/ castleisland/

Koch, WG (2009) State of the art of tactile maps for visually impaired persons. ICA SPIE Europe Symposium True-3D in Cartography, 24-28 August 2009, Dresden (Proceedings in print)

Rase, WD (2003) Von 2D nach 3D - Perspektivische Darstellungen, Stereogramme, reale Modelle. In: DGfK (ed.), Visualisierung und Erschließung von Geodaten, Kartographische Schriften, Bd. 7, Kirschbaum-Verlag, Bonn, 2003, 13-24 http://www.wdrase.de/Von2Dnach3D.pdf

Rase, WD (2009) Visualization of polygon-based data as a continuous surface. Manuscript 2009 http://www.wdrase.de/VisualPycnoInterEngl.pdf Technical report (in German) http://www.wdrase.de/PycnoInterReport.pdf

Renka, RJ (1988) Algorithm 660: QSHEP2D, Quadratic Shepard method for bivariate interpolation of scattered data. ACM Transactions on Mathematical Software, Vol. 14, No. 2, June 1988, 149-150

Schwarzbach F et al. (2009) Physical 3D models from LIDAR data as tactile maps for visually impaired persons. ICA SPIE Europe Symposium True-3D in Cartography, 24-28 August 2009, Dresden (Proceedings in print)

Tobler, WR (1979) Smooth pycnophylactic interpolation for geographical regions. In: Journal of the American Statistical Association, 74, 357 (1979), 519-535 http://www.geog.ucsb.edu/ tobler/publications/pdf_docs/geog_analysis/ Pycno.pdf 